\title{
La acción política no puede reducirse a cambiar los imaginarios sociales: una crítica a la relación entre estética y política
}

\author{
Political action cannot be reduced to changing the \\ social imaginary: a critique of the relationship between \\ politics and aesthetics
}

\author{
Christian David Nuñez Prado \\ Magíster en Filosofía \\ Co-investigador del Grupo Praxis Ética y Filosofía Política \\ Universidad del Valle \\ Correo electrónico: christian.nunez@correounivalle.edu.co \\ https://orcid.org/0000-0002-5896-7631
}

\section{Resumen}

La intención de esta investigación radica en hacer un aporte en la discusión filosófica sobre los efectos de la inclusión de conceptos estéticos en la actividad política. Se expondrá la concepción ontológica de la imaginación de Castoriadis y se presentará la crítica de Schmitt al romanticismo, para comparar los efectos de la estetización de la acción política en los autores. El trabajo en su conjunto pretende servirse de esta comparación para dilucidar un problema más amplio: el de las ventajas y desventajas de la estetización de la acción política en las sociedades modernas.

\section{Cómo citar este artículo:}

Nuñez, C. D. (2020). La acción política no puede reducirse a cambiar los imaginarios sociales: una crítica a la relación entre estética y política. Revista de la Facultad de Derecho y Ciencias Políticas, 50 (133), pp. 281-308.

doi: http://dx.doi.org/10.18566/rfdcp. v50n133.a03

Recibido: 06 de septiembre de 2019.

Aprobado: 17 de abril de 2020. 


\section{Palabras clave}

Schmitt, Castoriadis, Estética y Política, Imaginación, Imaginario social.

\section{Abstract}

The intention of this paper lies in contributing to the philosophical discussion regarding the effects of including aesthetic concepts into political activity. Castoriadis' ontological conception of imagination will be exposed and Schmitt's critique of romanticism will be presented, in order to compare the effects of the aestheticization of political action in the authors. The paper as a whole pretends to take advantage of this comparison to elucidate a broader issue: that of the advantages and disadvantages of the aestheticization of political action in modern societies.

\section{Keywords}

Schmitt, Castoriadis, Aesthetics and politics, imagination, social imaginary.

\section{Introducción}

La intención de esta investigación radica en hacer un aporte en la discusión filosófica sobre los efectos de la inclusión de conceptos estéticos en la actividad política. Esta relación fue develada por Walter Benjamin con el término 'estetización de la política' (2003), con el que indicó el movimiento de conceptos de la esfera del arte hacia las relaciones políticas.

Durante la modernidad, el intelectualismo, la racionalización de la vida y varias esferas de valor buscan reemplazar la certeza ontológica derivada del Dios creador. La razón práctica toma, por ejemplo, la función de ordenar y dar forma inmanentemente a la vida en común. El arte, luego de tornarse autónomo, es otro candidato a asumir ese rol. En este caso: "no se trata solamente de que el arte se conciba como fin en sí, independientemente de otras búsquedas humanas, sino que se asume como el fin en sí al cual debe quedar subordinado cualquier tipo de consideración” (Acosta y Quintana, 2009, p.56). Bajo esta concepción, la política se convierte en una suerte de obra de arte (Paredes, 2009). Se comprende el ejercicio político como creación artística donde la actividad creativa vale por sí misma y determina un actuar práctico que entiende lo verdadero y lo bueno con la estructura de lo bello (Paredes, 2009). La política estetizada tiene su génesis en la autonomía de la esfera artística. 
Se toman como punto de partida dos concepciones contrapuestas de la relación entre estética y política. Por un lado, la progresiva inclusión de conceptos estéticos en la política ha sido criticada por Rousseau, Weber y Schmitt (Paredes, 2009), entre otros. Dado que el efecto de esta expansión supedita las categorías rectoras de la actividad política a criterios artísticos y, como lo señala Weber, incita a la "elusión de la responsabilidad del juicio ético [que] tiende a convertir los juicios éticos de valor en juicios de gusto” (Weber, 1997, p.440).

Por otro lado, la relación estética y política defendida por Rancière, (Paredes, 2009) Gadamer, (Gama, 2009) Welsch, (Guefione, 2013) Nietzsche y Castoriadis, entre otros, sería una relación de solidaridad. La creatividad del arte sirve aquí de modelo para renovar la acción política y concebir nuevas formas de comunidad. El arte sirve ahora para pensar la realidad como tal con su capacidad de crear y recrear la esfera del sentido.

En el primer apartado se expondrá la ontología de la imaginación de Castoriadis y se trazarán los principales aspectos de su concepción política. En el segundo se presentará la crítica de Schmitt al uso de la imaginación por parte del Romanticismo y sus consecuencias políticas. En el tercero se va comparar la estetización de la acción política: mientras Castoriadis reivindicará la identificación de la actividad imaginativa con la acción intramundana; Schmitt proseguirá una lectura negativa de los efectos de la estetización de la acción.

Como conclusión se llevará a cabo la comparación entre Schmitt y Castoriadis, para dilucidar un problema más amplio: el de las ventajas y desventajas de la estetización de la acción política en las sociedades modernas. Al ampliar las consecuencias de esta polémica podría postularse como pregunta rectora lo siguiente: ¿Es la estetización de la acción política un muy bien camuflado conservadurismo político?

\section{La comprensión de la imaginación en Castoriadis}

Castoriadis adjudica el descubrimiento de la imaginación radical a Aristóteles en su De Anima, libro III (Aristóteles, De an. III, 1425b5). Aquí Aristóteles "introduce de pronto y sin advertir una phantasia completamente diferente, sin la cual no puede haber pensamiento y que probablemente precede a todo pensamiento" (Castoriadis, 1997, p.135). Castoriadis (1997) define la imaginación como "el poder (capacidad, facultad) de hacer aparecer 
representaciones que proceden o no de una excitación externa" (Castoriadis, 1997, p.140). La realidad empírica, cosa en sí, la X kantiana, no es objeto de conocimiento posible. Lo real es una especie de paleta en blanco más o menos indiferenciada, ininteligible que crea un shock (Anstoss) e impresiona la imaginación productiva, así la realidad es "coloreada” de manera arbitraria para producir representaciones posibles de conocimiento. De la X emerge solamente un mundo de representaciones.

En su desarrollo del concepto, Castoriadis critica a Kant, en tanto la imaginación kantiana no puede crear nada desde sí, pues está enmarcada en un sujeto trascendental cuya organización de las facultades subordina la imaginación al entendimiento. Aún en el desarrollo estético en la tercera Critica, el libre juego de las facultades está en conformidad con las leyes del entendimiento y la imaginación presenta "en la intuición las ideas de la razón” (Castoriadis, 1997, p.152). Castoriadis critica los planteamientos que vinculan el funcionamiento de la imaginación a "los requisitos del conocimiento verdadero" (Castoriadis, 1997, p.151).

Castoriadis proporciona a la imaginación kantiana la orientación radical de Fichte, para después sobrepasarlo. Como consecuencia, identifica la imaginación con el principio último y deduce que lo real no puede ni ser determinación absoluta ni caos, pues se presta para ser continuamente determinable por el poder formante de la imaginación (Curtis, 1997). Si en Kant el sujeto ya era capacidad formante, en tanto recibe pasivamente una impresión sensorial y con ella construye un mundo coherente mediante el entendimiento, en Castoriadis esta relación sensibilidad-entendimiento es dinamizada con la concepción de una sensibilidad activa que selecciona arbitrariamente lo que conoce. En el terreno epistemológico, el sujeto absoluto es "capacidad de hacer ser para él lo que es algo distinto a él [...]. El sujeto es capaz de hacer lo que siente, lo que para él deviene presente” (Malaver, 2005, p.118).

Castoriadis (2005) define la representación como organización temporal en imagen, compuesta de otras imágenes, pasiones e intenciones. La imaginación productiva permite conocer el mundo y a la vez hacerlo, la naturaleza de las impresiones sensoriales no es definida por un aparato objetivo de pensamiento; sino por lo agregado de la espontaneidad imaginativa a lo real. La imaginación productiva, como un demiurgo, crea un mundo de representaciones y encierra en ellas toda experiencia posible. 
Existen, entonces, dos aspectos de la imaginación productiva: uno en el sujeto absoluto (la sociedad) y otro en el individuo. La imaginación radical crea la imaginación individual como un lugar donde se asientan sus imágenes; mas la imaginación productiva individual no es absorbida del todo por su creadora sino que, a modo de oposición, esta conserva su espontaneidad para producir representaciones diferentes a las puestas por el sujeto absoluto.

Según Castoriadis: "se trata en los dos casos de una vis formandi-a-causale" (1997, p.133). Castoriadis le concede un estatuto ontológico a la imaginación productiva que tiene la creación como concepto esencial. La imaginación individual es operativa sólo después del despliegue y autolimitación de la imaginación radical en sociedad, entendida como representaciones originales que dan la pauta para la experiencia instituida dentro de la sociedad. El mundo social es una creación imaginaria de constelaciones de sentido que organizan el mundo (tanto biológico como social), delimitan el conocimiento y la acción posibles en un periodo de tiempo.

Para Castoriadis lo imaginario funciona a través de dos lógicas a la vez contrapuestas y solidarias, a saber, la conjuntista-identitaria (ensídica) y la magmática. La lógica conjuntista-identitaria o ensídica y la magmática constituyen cada una, una dimensión de lo que es esencial para el lenguaje y para toda vida y actividad social. Estas son desarrolladas en la obra más sistemática de Castoriadis: La institución imaginaria de la sociedad (1975), donde busca criticar los presupuestos ontológicos de la filosofía en su conjunto, al rebatir la concepción del ser como determinación e instaurar una ontología de la indeterminación.

En primer lugar, vamos a explicar la lógica ensídica. Castoriadis atribuye a una parte de la realidad ser susceptible de organizarse de acuerdo con la teoría de conjuntos, principalmente porque la ordenación del mundo reúne arbitrariamente elementos no idénticos en una concordancia cualitativa, sin agotar todas las características de cada elemento ni la cantidad de conjuntos posibles.

En la lógica ensídica, el principio de no contradicción determina la pertenencia de un elemento a un conjunto que de otra manera permanecería indeterminado. La función simbólica es inherente a la posibilidad del lenguaje, con la que se establecen relaciones prácticamente unívocas entre términos. La ordenación del mundo en conjuntos instituidos por la sociedad no utiliza solamente al lenguaje como algo exterior a las cosas que designa; también 
como instrumento para la acción dentro del mundo de la significación, pues cada representación refleja una realidad densa incognoscible sin la atribución de sentido social.

La dimensión conjuntista-identitaria establece una relación suficientemente determinada entre elementos pero, según Castoriadis, el lenguaje no se agota en esta dimensión, porque la posibilidad de creación de nuevos términos lingüísticos genera no sólo nuevos signos sino nuevas significaciones y sentidos. Por consiguiente, es imposible fijar los elementos del lenguaje absolutamente, por eso la teoría de conjuntos sólo sirve para explicar una de sus características, donde falta el elemento vivo y creativo: el magma.

Este concepto se refiere a la porción indeterminable e interminable de lo real, a la que la subjetividad absoluta ha impuesto límites de forma arbitraria para ser susceptible de albergar conjuntos, lo que es está sujeto al modo de ser del magma (Castoriadis, 1989). Los magmas sociales tienen límites virtuales evanescentes, esto es, establecidos temporalmente por la lógica ensídica para designar diferentes entidades; pero el magma con su constante vitalidad y transformación hace imposible dotarlos de una forma insuperable (Klooger, 2009).

En el magma, la significación tiene una relación con lo real que choca con el principio de contradicción, es decir, el magma tiene una forma de ser contradictoria respecto de los términos ensídicos que utiliza para hacerse efectivo. Aquí una forma no es X o Y o Z sino que es a la vez X, Y y Z. Las significaciones no ocupan un lugar determinado y, por tanto, no se oponen unas a otras: "Toda descomposición en elementos es aquí un artefacto provisional" (Castoriadis, 1989, p.182). El magma no tiene fronteras y cualquier separación asegura sólo una pertinencia temporal.

Para enlazar lo ensídico y lo magmático, Castoriadis otorga a la significación un rol fundamental en la vida social, porque es una creación ontológica “acerca de lo que es y la manera en que lo es” (Castoriadis, 1989, p.104). En definitiva, la red de significados que determina la sociedad se encuentra subordinada a la indeterminación del elemento imaginario del magma. El lenguaje, concebido como un código está inserto en un magma siempre en movimiento, como un lenguaje vivo, se crea a sí mismo, va más allá de cualquier significación establecida. 
Sin esta contraposición de ideas no se podría explicar la creación humana ni la alteridad entre sociedades o momentos de una misma sociedad: "El hombre no produce simplemente su vida, ni siquiera simplemente los medios de su vida, produce —como hombre social-histórico— las estructuras en las cuales vive, y esta producción genera el surgimiento de nuevos significados imaginarios encarnados en sistemas simbólicos” (Castoriadis, 2011, p.103).

La creación en el sentido radical aparece sólo cuando se erige un "nuevo sistema de axiomas” (Castoriadis, 2011, p.103) por parte del sujeto social. El mundo cambia cuando cambia la significación. La creación surge porque permite expresar otra cosa con el mismo lenguaje. Las significaciones imaginarias sociales, expresiones de la lógica ensídica, componen el lenguaje. Para Castoriadis, estas son esencialmente sociales e históricas, pues hacen parte de un período fijado dentro de un encadenamiento de momentos históricos anteriores y expresan un instante del medio social.

Ya expuestas la lógica ensídica y la magmática, opuestas y a la vez complementarias, se puede explicar cómo funciona la relación entre imaginación radical e imaginación individual, enfocándose especialmente en explicar cómo surge la creación en ambas y cómo se transforman interrelacionándose.

\section{- Individuo y sociedad}

Según lo expuesto anteriormente, la forma social da un sentido primordial a la vida de los individuos, ellos expresan y siguen con sus acciones y pensamientos el entramado posible/imposible creado por la realidad social. Los individuos pueden hacer cosas nuevas, pero sólo dentro de los límites de la sociedad.

Sin embargo, para Castoriadis la sociedad como impulso creador está siempre transformándose a sí misma, ya sea con las acciones y palabras vivas de los individuos o a través de la creación ex nihilo de sí misma. Esta doble capacidad creativa implica la superioridad de la sociedad y los individuos sobre cada forma de ser objetivada en un momento dado. Por tanto, la sociedad y sus individuos son indeterminación ontológica y epistemológica que usan la determinación como forma de expresión.

En la mayoría de los casos, el individuo es pasivo ante estos cambios de sentido y sólo puede seguir los dictados de la sociedad, pues la agencia 
individual es puesta primordialmente por la sociedad. A la expresión social primordial de formar individuos, Castoriadis lo denomina heteronomía, con ella señala la adhesión inconsciente a una ley. La heteronomía como dimensión inherente a lo social consolida formas necesarias de comportamiento y acción con la función de obligar explícita y autoritativamente a los individuos (Castoriadis, 2005). La sociedad controla y automatiza el discurso de los individuos y establece el sentido de su vida dentro de las instituciones sociales. Bajo la idea de heteronomía, los individuos actúan espontáneamente; pero lo hacen obedeciendo el sentido social.

Al tener la racionalidad coaptada, el individuo pierde la voluntad para cambiarse a sí mismo racionalmente. Sin embargo, posee una imaginación radical para generar un cambio sin depender de las imágenes sociales. Aquí la oposición ensídico/magmático se torna en instituido/instituyente, pues la constante indeterminación del magma abre la posibilidad para trascender el sentido instituido y dar paso a la cualidad instituyente del imaginario social.

Vista de esta manera, la acción no depende del componente racional, medios-fines, para transformar el mundo de acuerdo con principios sino de la espontaneidad de la imaginación radical.

\section{- Acción y Política}

La dimensión imaginativa social funciona como una transposición a gran escala de la capacidad individual de ver en una cosa lo que ella misma no es, es decir, la capacidad de otorgar significados novedosos a lo que es a partir de imágenes. Esto tiene como consecuencia la variabilidad de significaciones imaginarias sociales a partir del cambio en el sujeto absoluto. En este contexto surge la pregunta: en esta concepción de la imaginación, ¿cómo puede el hombre genuinamente actuar, en vez de recibir pasivamente las reglas en las que se enmarca su acción?

Castoriadis encuentra la respuesta en el concepto de praxis marxista transformado por el “idealismo y el romanticismo alemán” (Joas, 1998, p.149). Castoriadis asocia la forma como "Marx adscribió a la acción humana una capacidad creativa para producir objetos nuevos o formas sociales nuevas" (Joas, 1998, p.148-149) con la fuerza original de la imaginación de crear y recrear constelaciones simbólicas. 
Para contrarrestar la determinación de la sociedad instituida, Castoriadis utiliza la praxis con el objetivo de implantar representaciones novedosas. En la praxis lo nuevo se mezcla con lo viejo para hacer nuevas instituciones y resignificar las antiguas. Así, el hacer humano está siempre en relación posible con la objetivación novedosa de representaciones y la acción humana se dirige hacia algún lugar como proyecto.

La praxis basa entonces su acción en un conocimiento actual y en una proyección de ideas más allá del pensamiento. Como proyección de una representación futura, la praxis debe estar dispuesta al cambio impuesto por el resultado de su acción. Este tipo de acción debe ser flexible, pues hace emerger nuevos conocimientos y nuevos parámetros para la acción. De esta manera, Castoriadis ataca la concepción filosófica, donde la acción es racionalizada mediante imperativos antepuestos a la experiencia: "theory cannot be given beforehand, because it constantly emerges of the activity itself" (Castoriadis, 2005, p.76).

La praxis es la representación específicamente humana que tiene como fin "el fomento de la autonomía de la cual al mismo tiempo nace” (Habermas, 1993, p.388). Esta novedosa representación social no asume una posición totalizante ni se aferra absolutamente a una creencia sobre lo instituido; al contrario, busca clarificar mediante la reflexión las representaciones sociales, al compararse con ellas para abrir la posibilidad de actuar sobre ellas conscientemente: "el agente, al tomar la iniciativa, trasciende las determinaciones dadas y establece un nuevo comienzo" (Habermas, 1993, p.389) y, por tanto, "produces and encounters the new, the real as such" (Castoriadis, 2005, p.76).

Con la praxis, Castoriadis busca elucidar cómo debería ser una subjetividad propiamente política, pues antes de ella, sólo existe fabricación de individuos por parte de la sociedad. Esta representación cambia los individuos y las instituciones, pues enmarca la acción futura bajo una proposiciónimagen y con ella transforma la sociedad sin dejar de lado el constante cambio en su interior.

Castoriadis define su concepto de política como la actividad que pone en cuestión de forma explícita y lúcida la institución de la sociedad (Castoriadis, 1991). La actividad política presupone la filosofía, representación social con la tarea de cuestionar todas las representaciones instituidas, pues no admite ningún elemento necesario o natural en ellas y las concibe como creaciones simbólicas humanas o convenciones. 
La política busca entonces la fuerza instituyente del imaginario social. La política es la autonomía común o, con otras palabras, el proceso creador de decidir qué reglas regulan la vida social con la participación de todos. La política se inserta en el mundo social-histórico como una representación social y hace uso de la filosofía, es decir, de la interrogación sin fin sobre la forma de las Significaciones Imaginarias Sociales-SIS, para desmitificarlas y convertirlas en referentes para el pensamiento y la acción transformadora.

Para Castoriadis, la acción política aparece porque no hay correspondencia entre las SIS instituidas y las irrupciones instituyentes del imaginario radical social e individual. Esta disyuntiva genera nuevas posibilidades de ser y estimula a los individuos a actuar de forma distinta y plural. La política es una "empresa supremamente paradójica que consiste en crear formas de pensamiento para pensar lo que está más allá del pensamiento, lo que simplemente es” (Castoriadis, 1986, p.134). La acción política es concebida, esencialmente, como una transgresión al orden establecido y un acercamiento a lo real, al magma.

Sin embargo, la acción política, nacida de la irrupción de la imaginación radical individual o social, no necesita ser compartida inicialmente por toda la sociedad; pero viene dotada de esta posibilidad, porque desde su inicio está configurada como capaz de ser insertada en el lenguaje. La acción significativa sólo necesita cuestionar los presupuestos compartidos públicamente para insertar una nueva representación.

En Castoriadis es problemático situar las transgresiones de la política en el terreno de la posibilidad, pues no se puede dominar su resultado ni saber con certeza su fundamento, dado que la sociedad y el individuo tienen sus propias lógicas magmáticas y constantemente están realizando una acción sobre la acción aplicada sobre ellos. La inserción de una representación social novedosa no implica una transformación, al menos no en un sentido deseado por un agente, porque la acción política no puede, en principio, diferenciar un actor ni determinar con exactitud desde qué imaginario nace la acción (Habermas, 1993).

Aunque la proyección de la imaginación impulsa una acción novedosa e independiente dentro de la sociedad, Castoriadis admite lo excepcional y espontáneo de este tipo de acción y su proyecto de autonomía intenta convertir la novedad en regla para el individuo y la sociedad. 


\section{- Acción Política}

La política toma forma como proyecto de autonomía, esto es, el proceso instituyente por medio de la cual la praxis inserta una nueva representación en el mundo. La autonomía es definida como la capacidad de auto-legislarse y autorregularse de la sociedad que se encarga de asumir la agencia de la decisión política: hacer y rehacer sus propias reglas.

La forma por antonomasia de esta política es la democracia, entendida como la forma ideal o imagen que da sentido a un conjunto de acciones y logra la instauración de la interrogación sin fin sobre las formas sociales, para asegurar la participación de todos en la transformación constante del sentido de ley primordial instituido por la sociedad.

En la democracia, entonces, los hombres tienen consciencia de la nonecesariedad de las reglas, pues ninguna está cerrada al escrutinio de su significación. Todo se presenta como transformable y se enfatiza el sentido colectivo de la decisión de mantener o no cierta significación como válida. Esto lleva a desplegar una actividad instituyente constante, mediante la consciencia del cambio de significado en las palabras.

Según Castoriadis, la característica fundamental del hombre es su capacidad de crear y ser delimitado por representaciones, razón por la cual el ser humano está condenado a experimentar constantemente con lo nuevo y ser él mismo de diferentes maneras. Además, atribuye al lenguaje la capacidad de convertirse en un instrumento político, aunque sólo después de la aparición de la autonomía como representación social, que aprecia y fomenta la polisemia del lenguaje.

Para Castoriadis, entonces, el debate social es el garante de la acción política, ya que parte del hecho de la inclusión en la política de toda la comunidad lingüística, pues todos están inconsciente y constantemente participando en la actualización de las significaciones sociales y pueden empezar o participar en un movimiento instituyente de significado sobre las significaciones nucleares instituidas. Esto puede tener como consecuencia el comienzo de un nuevo curso de acciones. Con el debate, este proceso instituyente de significados, ligado a la acción espontánea del sujeto autónomo social, se refiere a una representación social que genera la intención en los individuos de contemplar lo dado por el imaginario y preguntarse qué hay que hacer con él, es decir, "el pasar por la razón al imaginario" (Castoriadis, 2011, p.175). 
En conclusión, Castoriadis concibe la democracia como la culminación política de una sociedad autónoma en su diseño que incluye potencialmente todas las opiniones y les hace justicia. Lo importante en el proceso democrático es aumentar la autonomía de la sociedad, por eso, cada objetivo comúnmente delimitado debe ser tomado con una seriedad limitada, en tanto puede aparecer una nueva posición donde se oriente mejor la acción. En Castoriadis toda acción política o su consecuencia está entonces inserta en la posibilidad. El cambio, sustentado en el poder magmático de la imaginación, es inherente a la idea de creación, para Castoriadis esta idea es una y lo misma con la responsabilidad política.

\section{Comprensión de la imaginación en Schmitt}

\section{- La subjetividad romántica}

En Romanticismo Político (1919), Carl Schmitt hace una crítica exhaustiva al Romanticismo, que sirve como modelo histórico para la comprensión de la sociedad centrada en la crítica por parte de los sujetos a los fundamentos del orden político. En él se puede entrever la manera en que una "apertura histórica de sentido en torno a la cual se ordena la experiencia humana en un periodo" (Ramírez, 2009, p.61) es conquistada por los conceptos centrales de la esfera del arte. En otras palabras, para Schmitt gracias al Romanticismo se efectúa un cambio discursivo en la subjetividad política europea.

Schmitt utiliza el método de la teología política en su esfuerzo intelectual por definir el Romanticismo Político. Este consiste en buscar la estructura última de la política de una época determinada, a la luz de una concepción particular de Dios. Este método asume la analogía formal entre teología y política, además permite establecer la estructura última de los conceptos que rigen la práctica.

La ontología de la teología política le permite a Schmitt entender metafísicamente el Romanticismo, esto es, hacer inteligible su centro de gravedad, aquello "que los hombres consideran como instancia absoluta" (Schmitt, 2005, p.58), trascendente y esencial que da sentido a la existencia práctica en un periodo. El juego de las ideas de trascendencia e inmanencia (Rossi, 2002) le posibilita a Schmitt entender cómo la variación de la relación inmanenciatrascendencia del concepto de Dios determina el funcionamiento de una época. 
Por eso Schmitt ubica el Romanticismo dentro de los desarrollos conceptuales modernos, en tanto resultado del proceso de disolución espiritual iniciado con la modernidad para develar sus conexiones con diversas fuerzas espirituales, a fin de establecer la línea de progreso del movimiento romántico en términos sociológicos, políticos y filosóficos.

En el terreno de las ideas, Schmitt concibe el Romanticismo como una de las reacciones emocionales al racionalismo cartesiano del siglo XVIII. Este último plantea una escisión de la realidad entre pensamiento y realidad material. Escisión que determina todo desarrollo filosófico inmediatamente posterior como un intento por reestablecer una experiencia unitaria del mundo.

Uno de ellos es el Ocasionalismo, que en su "búsqueda de la realidad” por un camino alterno al racionalista considera al Dios cristiano como "causa de todo hecho particular, tanto psíquico como físico” (Schmitt, 2005, p.150). Dios interviene de ocasión en ocasión para darle unidad al mundo. Así, el Ocasionalismo concibe a Dios en términos deístas y lo convierte en un orden general, donde queda suprimida toda personalidad, al reducir su trascendencia y aumentar su carácter inmanente.

Dice Schmitt: “ahora bien, esta postura ocasionalista puede subsistir, pero al mismo tiempo poner en el lugar de Dios otra cosa como instancia máxima y factor determinante, por ejemplo, [...] el sujeto individual” ( 2005, p.58). Cuando esto sucede, se intensifican las consecuencias inmanentes de esta estructura de la acción de Dios, lo que conlleva en la práctica a una "reducción de la experiencia humana solamente al campo mundano” (Scatolla, 2008, p.112). El Romanticismo sería una forma de ocasionalismo donde el sujeto empírico es elevado a la posición creadora del Dios cristiano.

Esta reducción de la trascendencia, o mejor dicho, su explicación en términos inmanentes, se hizo mediante la torsión estética de la filosofía subjetivista de Fichte. Al intentar reestablecer una experiencia unitaria del mundo, Fichte eliminó la escisión dejada por Descartes a través de un Yo absoluto: "Éste emana de sí, de forma absolutamente activa, el mundo y se pone a sí mismo y a su contrario" (Schmitt, 2005, p.110), a saber, el Yo absoluto crea, antecede y contiene, pensamiento (yo) y mundo (no-yo). El Yo absoluto es el espíritu de lo viviente, la sustancia de la cual pensamiento y ser son atributos.

El no-yo, el mundo, se convierte en la materia a ser transformada por la actividad voluntaria del yo, con lo que se desarrolla una relación causal entre 
ellos. El yo puede transformar la materia del mundo de acuerdo con los dictados de su voluntad, puestos por el Yo. Esto porque el yo está subordinado al Yo:

El mundo, el no-yo, se convierte en Fichte en la materia que debe ser elaborada. Debe ser transformado en "causalidad absoluta” y actividad absoluta. Por eso, la intervención en el mecanismo de las relaciones causales de la realidad exterior se vuelve necesaria y debe suponerse una [...] adecuada relación de causa y efecto. (Schmitt, 2005, p.144)

Con la torsión estética de Fichte sucede una reorientación de la actividad del yo que surge de la supresión de la jerarquía entre las diferentes realidades: Yo y yo. Se rompe la legalidad trascendente de los dictados del Yo sobre el yo, se combinan y el yo adquiere las características del Yo: la capacidad absoluta de crear el mundo y a sí mismo; pero proscribiendo la acción voluntaria sobre el no-yo. De esta forma, se iguala el principio ontológico con el principio psicológico.

Esta igualación entre trascendencia e inmanencia deriva en una configuración psicológica, cuya epistemología es la sensibilidad y el criterio para juzgar las acciones individuales es subjetivo. Es un cambio en la concepción de la moralidad: un juicio moral presupone la primacía de un principio racional condicionador de la acción, un juicio estético subordina los principios racionales a principios sensibles determinando de otra forma la relación de la subjetividad con la percepción y conceptualización del mundo compartido. Los significados supra-individuales y objetivos, que daban estabilidad a la identidad personal y a la jerarquía de la vida en sociedad, empiezan a ser entendidos como un estándar que impide la expresión de la individualidad. Esta estancia psicológica implica una igualdad moral de la experiencia de cada uno, que hace imposible criticar las acciones de los sujetos desde un punto de vista extra subjetivo.

Según Valdecantos: "lo esencial aquí es que esas vivencias están todas al mismo nivel y no hay concepto con qué distinguirlas ni instancia que decida sobre ellas; cada una será, en su propio momento, una potestad absoluta” (2013, p.154). Que la trascendencia sea explicada en los términos de la inmanencia es la reivindicación de la relatividad, porque no se diferencia entre esencia y apariencia, al contrario, se toma esencia por apariencia.

El derecho, la moralidad, la ética, la política, etc. daban en Fichte un contenido para el ejercicio de la voluntad humana. Con la torsión romántica, la 
acción del hombre se sitúa en el poder predicador de la imaginación, en donde una voluntad flotante es subordinada al deseo de expresión individual, esto crea reglas propias de vida siempre abiertas a un nuevo proceso de creación. El yo se realiza cumpliendo sus propios dictados y renuncia a la capacidad de juzgar: "como no sea que se entienda por juicio cada uno de los eslabones de una infinita cadena de ocasiones del ingenio [...] que jamás se pronunciaran de manera definitiva ni decisiva, ni con el propósito de determinar, definir o concluir" (Valdecantos, 2013, p.153).

Esto representa un cambio discursivo identificado como una apertura del lenguaje a la negación del principio de no contradicción. Con el cual el concepto de causa es reemplazado con el concepto de occasio. El individuo combina y ordena experiencias, conforme al poder sintético y unificador del sujeto kantiano y fichteano, además genera pautas de comportamiento personales sin necesidad de adherirse a ningún consenso comunitario. Con el poder de su imaginación, entendida como imaginación productiva, trasciende toda configuración objetiva de la realidad:

En el sentido de una acción o causa, la palabra tiene causa tiene también el sentido de un vínculo teleológico o normativo y de una coerción espiritual o moral, que permite una relación adecuada. Por el contrario, entre occasio y efecto se da una relación absolutamente inadecuada; es -dado que cualquier pormenor puede ser occasio de un efecto incalculable, por ejemplo, la contemplación de una naranja, para Mozart, la ocasión de componer el dueto "Lá ci darem la mano"- completamente inconmensurable, reticente a toda objetividad, a-racional, la relación existente en lo fantástico. (Schmitt, 2005, p.146)

Por esto, en el Romanticismo la realidad objetiva es vista como algo falso, limitante, irracional. En cambio, la posibilidad es concebida como el lugar donde se está constantemente creando la vida. La realidad empírica sólo puede ser comprendida como una estructura artificial insignificante que anquilosa el poder creador subjetivo, una creación simbólica evanescente y virtual como en el caso de Castoriadis.

De esta apertura del lenguaje al poder predicador del individuo que renuncia al principio de no contradicción, Schmitt deriva la característica principal del sujeto romántico: la ironía como forma de ser de la subjetividad y no sólo como figura retórica. Esta tiene la función de inhibir sobre el sujeto romántico el sustrato objetivo de los conceptos sociales. La ironía como figura retórica 
busca decir lo contrario de lo que se piensa: "el fenómeno no es la esencia, sino lo contrario de la esencia” (Kierkegaard, 2000, p. 275). Con la ironía como forma de ser, el individuo es siempre "consciente de que su apariencia es lo opuesto a lo que él mismo se atiene con firmeza” (Kierkegaard, 2000, p.277).

La oposición a los significados objetivos no se realiza, debido a que el concepto sobre el cual se efectúa la ironía no indica, en realidad, que esta oposición sea la expresión final un pensamiento. En consecuencia, se niegan los conceptos con la ironía como figura retórica, pero: "la negación es negada cuando el sujeto con su forma de ser tampoco asume lo que niega, entonces toda limitación de la personalidad es superada en un proceso infinito de creación personal” (Schmitt, 2005, p.131-132).

Aquí la ironía denota ante todo el ejercicio continuo de convertir todo contenido dado en la experiencia en objeto de un tipo particular de reflexión y después convertir la reflexión misma en la base para una nueva reflexión. Este tipo particular de reflexión es la apropiada para la esfera del arte; sin embargo, como se mezcla con los conceptos sociales, políticos, económicos, etc., la subjetividad romántica "está en un registro metafísico" (Kierkegaard, 2000, p. 283), porque intenta destruir el carácter nomológico de la realidad social desde su persona y niega discursivamente toda existencia extra-subjetiva.

Con la ironía, la subjetividad romántica lleva contenida inevitablemente lo que Schmitt llama una "ética de la conformidad” (Schmitt, 2005, p.109), cuya esencia es la indecisión surgida de la renuencia a la autodefinición y, con ello, su acción en el mundo sufre una inversión altamente irónica.

Por un lado, buscan fabricar irónicamente la ocasión y hacen de este tipo de recurso su estilo de vida. Transforman las causas en ocasiones para la creación de un discurso personal novedoso y escapar al compromiso con la realidad social. Por otro lado, el individuo queda a merced de la legalidad de los conceptos de la realidad objetiva que no ha sido cambiada por medio de la acción práctica y, por tanto, no han dejado de funcionar por fuera de sus construcciones irónicas del discurso.

De acuerdo con Durst: "The more the romantic subject seeks a safe haven in social discourse, the more it becomes in 'the praxis of daily life' a usable object” ( 2004, p.55). A pesar de la retórica activista, el sujeto romántico no sale del juego de la imaginación consigo mismo, deja intacto el mundo externo y se somete a él. El resultado de la acción política ocasionalista es pasividad 
pura pues no permite, merced de la ironía, una oposición fáctica ante lo presente. Esta subjetividad “actúa” en un mundo ficticio y su superioridad sobre el presente es sólo retórica.

\section{- ¿Qué significa la estetización de la acción política?}

Para situar las conclusiones sobre el romanticismo de forma correcta, se debe hacer alusión a las raíces weberianas y hegelianas de las categorías que Schmitt utiliza en su crítica al Romanticismo. En clave teológico política, esto significa que Schmitt usa el método de la sociología crítica de Weber, manifestada en su teoría de las esferas de acción dentro de una empresa más hegeliana de "reconducción de una época histórica a un fundamento intelectual unitario” (Villacañas, 2008, p. 114).

Según Villacañas: "hay un momento en que Schmitt cita a Weber sin reparar en ello. Cita, [...] su teoría de las esferas de acción [...] elige aquella metáfora de la 'lucha de las divinidades'” (2008, p.64), para exponer la lucha imperialista de lo estético contra otras esferas de la vida.

La teoría de las esferas de acción es una "descripción antropológica y axiológica de la forma en como los seres humanos orientan sus acciones, decisiones e interacciones sociales” (Mèlich, 1995, p.147) con la cual Weber analiza el proceso de racionalización occidental, cuando la religión pierde su carácter absoluto y pasa a compartir la dirección de la vida de los individuos con la economía, la política, el arte, la vida sexual y el conocimiento científico (Weber, 1978).

Estas esferas se afirman sin la religión y la acción humana se organiza de manera escindida en múltiples dimensiones. Cada esfera se organiza conceptualmente a partir de los diferentes valores a desarrollar en diferentes espacios de la experiencia, con la consecuencia práctica de la instauración de acciones específicas en cada caso. Según Weber, entre las esferas hay límites; pero no jerarquías, lo que desemboca en una lucha inevitable entre los valores de las distintas esferas dentro de la vida de las personas.

El arte es una más de estas esferas, se impone a sí mismo una autonomía conceptual que posee sus propias leyes, instituciones, valores y principios 
de legitimidad ${ }^{1}$ (Lipovestky \& Serroy, 2013). Un arte soberano en su propia esfera: Lart pour l'art, donde el contenido autotélico de la esfera artística excluye criterios no estéticos, es la antesala de la expansión imperialista de los criterios artísticos hacia todas las esferas de la experiencia llevada a cabo por el movimiento romántico.

A diferencia de Weber, Schmitt postula una pretensión de soberanía en cada esfera, pues aspiran a asumir la función asignada a la religión de dirigir la vida en comunidad. La idea de un centro absoluto de una época se combina con la idea de una experiencia multidimensional y da como resultado una estructura metafísica que puede tener cualquier esfera como soberana en diferentes momentos. Si se agota un tipo de metafísica, las esferas se reordenan. De esta forma, los asuntos religiosos, morales, políticos y científicos siempre tienen su legalidad propia, aunque condicionada por la esfera soberana en cada momento.

La centralidad del concepto de soberanía como problema a resolver en la modernidad se debe a que es justamente la interpretación de la soberanía la trastocada al desplazarse las esferas centrales dentro de la estructura metafísica. Por un momento, la estética ocupa el lugar soberano de la estructura metafísica del espíritu europeo, sólo así ella se hace una comprensión del mundo y transfiere sus principios centrales a todas las esferas de la actividad humana. El criterio de valor estético adquiere soberanía y, por tanto, las categorías centrales de l'art pour l'art se expanden a todas las esferas prácticas. Con ello, la política pierde su autonomía, su valor propio y las acciones políticas se convierten en expresión de valores estéticos.

Los criterios con los cuales se manipula la materia en las obras de arte se extrapolan al ámbito de las relaciones humanas: "de manera que una serie de fenómenos que tienen que ver con el ser-en-común de los seres humanos y con sus modos de relación se asume en términos del gozo, del éxtasis” (Acosta, Quintana, 2010, p. 56), de esta forma, con la exaltación romántica de la imaginación se distorsionan los compromisos duraderos con una idea propios de la esfera política schmittiana.

1 "academias, salones, teatros, museos, marchantes, coleccionistas, editoriales, críticas, revistas" (Lipovestky, Serroy, 2013, p. 15). 


\section{- La subjetividad política}

Si se quiere entender la crítica a los románticos y porqué desfiguran la acción política, es importante partir de cómo la acción política está asociada a un tipo particular de subjetividad activa que Schmitt propone "en un acto típico de enjuiciamiento intelectual e histórico con el que se separa netamente del espíritu de su objeto de estudio" (Valdecantos, 2013, p.154).

Schmitt condena una subjetividad política que representa el valor de la política impuesto por la estética, que extralimita sus acciones especiales. Schmitt construye lo político en exacta oposición a lo que considera como romanticismo político (Campe, 2016) y se interesa especialmente en destacar el valor del cual emana toda energía política: "la política es la esfera de acción que se atiene a la norma de la justicia como su dios propio y superior. Ese es su espíritu, aunque como tal tiene diferentes interpretaciones y, por eso, acoge diferentes luchas" (Villacañas, 2008, p.68). La esfera política autónoma debería subordinar toda acción a la capacidad de "diferenciar entre lo justo y lo injusto" (Schmitt, 2005, p.182).

Lo político es la acción de darle valor a la realidad empírica a través de normas definidas por la elección radical entre un valor y un desvalor (Ramírez, 2009), la cuestión es caracterizar esa subjetividad activa que busca, ante todo, conmover la realidad efectiva diferenciando entre lo justo y lo injusto (Schmitt, 2005). La forma de subjetividad propia de la política se puede describir, siguiendo a Ramírez (2009), mediante tres rasgos de lo político: normativismo, objetivación y oposición.

Primero, el normativismo es la elección libre de una idea política que da significado a la vida del individuo. Conforme la crítica hegeliana sobre la ironía romántica, Schmitt reproduce su idea de una individualidad apegada a los dictados de una idea compartida comúnmente. Dice Hegel: "el verdadero carácter incluye, por una parte, un contenido esencial de los fines y, por otra parte, el retener firmemente el fin, de modo que la individualidad perdería toda su existencia si hubiera de dejarlo escapar y renunciar a él” (Hegel, 1989, p.60).

Segundo, la objetivación busca realizar un estado de cosas de acuerdo con un principio normativo. Como ya se ha mencionado, en la acción política el sujeto no debe dar paso a reinterpretaciones después de hecha la elección. "Con esto, adicionalmente, se supera la escisión entre lo interno y lo externo, 
pues el estado de cosas alcanzado tras la objetivación visibiliza lo que hasta entonces estaba confinado a la interioridad del sujeto” (Ramírez, 2009, p.67). La subjetividad política modifica su entorno mediante la acción, configurándolo de acuerdo con los dictados de una idea elegida entre las que operan en la realidad efectiva.

Tercero, la oposición es consecuencia de las dos anteriores. Para Schmitt, elegir es oponerse a lo no elegido, es decir, el contenido de una elección es inconciliable con otro; dos ideas políticas no pueden ocupar el espacio determinante de la subjetividad en la esfera política. En este sentido, la vitalidad específicamente política nace de considerar una idea política como justa y oponerse lo injusto y, así, ordenar la realidad. Es con la "decisión ontológicamente fundada” (Diez, 2007, p.71) que Schmitt busca que las oposiciones estén claramente demarcadas y la lucha por una forma de vida se realice en el plano de lo político.

Las tres categorías del sentido de lo político tienen como presupuesto el concepto de lucha, que subyace toda la crítica de Schmitt a los románticos. Para Schmitt, el conflicto es necesariamente político y un componente estructural de la vida humana, además de esencial para asentar en la realidad efectiva una cierta idealidad y desterrar otra, es decir, para la acción política. En Romanticismo Político aparecen rasgos de la acción política que serán luego desarrollados en El concepto de lo político (1927).

En suma, "el sujeto de la acción política es alguien que articula su representación de sí mismo en torno a la adhesión afectivo-volitiva a una norma y, de este modo, se inmuniza frente el cambio continuo de impresiones y emociones" (Ramírez, 2009, p.67). La elección de una norma da un carácter militante a la subjetividad, pues esta se determina a partir de un concepto definido, articulando sus acciones con él, siendo activa en la transformación de su realidad efectiva y aceptando las consecuencias de sus acciones, aun la muerte.

Para Schmitt, entonces, el grado de seriedad en la identidad del sujeto depende de su obediencia y sometimiento a un contenido considerado absoluto. La falta de carácter propia de la subjetividad romántica, está ligada a la "variabilidad del contenido político de su decisión” (Schmitt, 2005, p.182). Por la ironía, el individuo no logra una decisión firme, ni establece compromisos con la realidad efectiva sino simplemente consigo mismo, lugar donde no hay necesidad $\mathrm{u}$ obligatoriedad alguna pues todo lo objetivo es un contenido de consciencia. 
La subjetividad romántica busca tener el control absoluto de crear la realidad desde sí misma, con lo cual se convierte en contemplativa, pues su "finalidad no es la producción de efectos, sino el placer de experimentar su misma emotividad” (Villacañas, 2008, p.66). Actividad propia del que piensa y reflexiona sobre los acontecimientos o ideas políticas donde "el impulso humano universal de expansión, de otro modo peligroso, sólo genera aquí libros gruesos" (Schmitt, 2005, p.85).

\section{La imaginación en la acción política: Schmitt y Castoriadis}

Este apartado toma como núcleo la discusión entre los principios de Schmitt y Castoriadis y se argumenta que, la indeterminación activa, propia de la subjetividad castoriadiana, tiene una estructura semejante a la ocasionalista romántica.

Castoriadis se puede categorizar como romántico en tanto centra su teoría en el aspecto ontológico de la imaginación productiva, su aspecto creador y destructor de mundos y colectiviza la idea de sujeto en ella sin coacciones materialistas ni imperativos morales toda creatividad, es decir, estetiza la filosofía de Fichte.

En la crítica de Habermas a Castoriadis encontramos líneas argumentativas entrecruzadas con la crítica de Schmitt al Romanticismo. Para Schmitt, el carácter autopoiético de la imaginación productiva, demostrado empíricamente por los raros momentos históricos donde "la masa de que están hechas las instituciones se torna otra vez líquida” (Habermas, 1993, p.389), diluye la capacidad humana para la acción política en tanto debilita la objetividad de toda causa.

Según Habermas, Castoriadis tiene que asimilar la praxis intramundana a la "praxis de los demiurgos sociales, creadora de lenguaje, proyectante de mundos y engullidora de mundos" (Habermas, 1993, p.393). Por eso, el concepto de praxis no está sometido a restricciones sociales, sino que:

Contiene ya el momento de la creación en un nivel [...] común, donde los comportamientos de los individuos, los grupos, las clases, sin dejar de permanecer en el interior del sistema social dado, constantemente 
producen la aparición de nuevas variantes. Siempre podemos decir que estas variantes eran posibles en el sistema, pues de otra manera no se hubieran podido materializar. (Castoriadis, 2011, p.137).

Se trata de una "praxis que coincide con la creatio continua de nuevas interpretaciones del mundo, con la génesis ontológica, [...] que proyecta épocas históricas y espacios sociales” (Habermas, 1993, p.393). El individuo no actúa ni en el momento de creación ni en la institución, pues la política tiene la misma plasticidad y espontaneidad de la imaginación. Además, cuando la producción del imaginario central o radical se detiene, "la sociedad se solidifica frente a sus propios orígenes” (Habermas, 1993, p.393), perdiéndose en sus propias objetivaciones. El resultado es un autoextrañamiento expresado en el concepto de heteronomía, superado sólo mediante un nuevo proceso creador “de una sociedad que se instituye a sí misma” (Habermas, 1993, p.393).

La idea de los límites y de lo real como autolimitación recuerda el pensamiento de Fichte. Castoriadis "se acoge a las figuras del pensamiento que nos son conocidas por la teogonía y por la Doctrina de la ciencia de Fichte” (Habermas, 1993, p.393).

La concepción de la acción política de Castoriadis es una interpretación accionista y estetizada de la praxis con claros rasgos románticos donde la sociedad, como el nuevo sujeto absoluto, personifica un demiurgo "poético" que extrae de sí tipos de mundos siempre nuevos para reconfigurarse 0 , mejor, autoinstituirse de manera indefinida.

\section{- ¿Por qué la estetización de la acción "pervierte" la acción política según Schmitt?}

De acuerdo con Vicañas: “Aceptado el destino de las esferas de acción, el romántico aparece como oportunista, ocasionalista e iluso” (Villacañas, 2008, p.69). Es con estas categorías que, desde la visión esencialista de Schmitt, la acción política al estilo de Castoriadis deja de lado dos detalles importantes: la lucha por la objetivación de un cierto valor en la realidad política y, como consecuencia, su realización el mundo empírico.

De acuerdo con la interpretación de Schmitt, la subjetividad política de Castoriadis impide una acción política consciente y reglamentada. Castoriadis 
aleja la política de los compromisos existenciales con una causa, propios de la política schmittiana. Estos compromisos pierden sentido si todos los principios son evanescentes y pierden el valor suficiente para identificar la vida con ellos. Sin embargo, para Castoriadis la política schmittiana significaría, al ligar la identidad personal a una causa: "mantener inactivas sus potencias intelectuales [ponderando] [...] la falta de reflexión sobre los que se hace, porque un enjuiciamiento certero llevaría a mejorarlo, o [...] a desistir dignamente del empeño” (Valdecantos, 2013, p.161).

Para Castoriadis la acción social debe crear nuevos valores políticos y pone espontáneamente nuevos conceptos que, a su turno, expondrán las deficiencias de los conceptos presentes en la realidad política en un fluir incesante de interpretaciones de acontecimientos. En Castoriadis entonces, desde el punto de vista de Schmitt, toda acción de los individuos es irracional, pues las razones para elegir una idea política se renuevan constantemente de forma indeterminada. Con esto queda destruida la objetivación de alguna concepción política y se pierde la pretensión de soberanía de los conceptos políticos, en tanto la crítica puede disolver los conceptos políticos adecuados para afrontar una situación determinada: "sobre todo de las tenidas por buenas y aun de las que lo son en verdad, si es que se puede seguir empleándose la alocución "en verdad” cuando la crítica ha empezado su tarea” (Valdecantos, 2013, p.161).

El concepto de historia de Castoriadis entraña la flexibilidad de la voluntad al no considerar un sistema de creencias como absoluto, lo cual Schmitt identifica como un cobertor de la pasividad política: "el romántico utiliza la palabra historia, al igual que el cristianismo, como cobertura de su pasividad" (Schmitt, 2005, p.187) y todo otro concepto político.

La actividad política en Castoriadis es concebida en términos primordialmente lingüísticos, acompaña los hechos histórico-políticos expresando su descontento al exponer la mejor forma de "hacer" las cosas en el mundo real, equiparando palabra y acción. La dimensión lingüística de la acción ponderada en Castoriadis como acción política consiste en "interpretar de otro modo lo existente” (Marx, 1974, p.14), para crear alguna idea con la intención de abarcar, sólo teóricamente, la situación del momento.

Schmitt demuestra la diferencia entre su posición y la romántica con el concepto de lucha. Schmitt recalca el carácter conflictivo o polémico de las ideas políticas, que tienen como trasfondo un debate sobre lo justo y lo injusto, 
donde la oposición entre ideologías políticas adquiere sentido (Villacañas, 2008). La decisión por alguna ideología implica la posibilidad de la lucha y muerte, en pos de la realización de una forma de vida considerada justa.

Con base en esta distinción, Schmitt rechaza la retórica revolucionaria romántica que exalta el conflicto en cualquier realidad y no como parte estructural de lo político: "su objetivo es diferenciar el sentido específico de 'lucha' que va asociado a lo político de otras acepciones más generales del término” (Rossi, 2002, p.65). La lucha política no es la del zapatero con el cuero o las concepciones liberales del término como competencia económica. Para Schmitt, el conflicto es necesariamente político y por eso "enfatiza en el sentido originario del término, esto es, en el carácter físico de la posible lucha con el enemigo y el hecho de que en esa eventualidad esté comprometida la posibilidad de la eliminación física” (Rossi, 2002, p.65).

La acción que tiene por premisa un dogma, entonces, se ve subvertida por un individuo irónico, una persona que vive a espaldas de la realidad política, sin un centro de gravedad propio, la crea constantemente, sin restricciones y, por ende, sin acciones específicamente políticas. El sujeto político de Castoriadis, la sociedad, tiene por eso el mismo tipo de carácter.

\section{Conclusión: la acción política no puede reducirse a cambiar los imaginarios sociales}

Castoriadis hace parte de una generación de autores que en los años 60 y 70 criticaron las categorías fundamentales de la filosofía marxista y su crítica al capitalismo. La crítica de Castoriadis a los principios del marxismo subvierte sus conceptos revolucionarios. En la lectura de Tormey y Townshend (2006), Castoriadis es catalogado como posmarxista en la medida que se mantiene dentro de la órbita de las problemáticas marxistas; pero busca respuestas a estas preguntas en otras ramas del conocimiento. Lo importante en este caso, es la inversión de Castoriadis a las categorías usadas por Marx para fundamentar la realidad social.

El marxismo ortodoxo, con su método positivista, es deficiente para Castoriadis, pues se aferra a una causa material absoluta y desde ahí intenta explicar todas las interacciones sociales. Por el contrario, Castoriadis enfatiza la creatividad de la sociedad e invierte la fórmula de Marx: determina la infraestructura por parte de la superestructura. 
Castoriadis busca destruir el reduccionismo marxista y explicar la sociedad en términos alternativos al materialismo histórico, concentrándose específicamente en la cuestión del sentido, el lenguaje y el significado. Esta inversión de principios, para Marx y Schmitt, pierde de vista el carácter transformador de la acción y se concentra en principios abstractos y construcciones conceptuales. Esto implica que la lucha política se da contra significaciones y que, al "combatir solamente las frases de este mundo, no combaten en modo alguno el mundo real existente” (Marx, 1974, p.18).

En esta línea, los intentos de la filosofía subjetivista de Castoriadis que toma la realidad como el producto de la conciencia absoluta son una forma de pasividad política y un perfecto conservadurismo. El marxismo, por su parte, considera necesario llevar a cabo una ruptura, una acción transformadora de la sociedad, ruptura que implica el compromiso con la causa proletaria como opuesta a la burguesa y el ejercicio de una praxis que modifique, también mediante la violencia, el orden socioeconómico. De manera similar, en Schmitt el concepto de lucha física es un componente cardinal de la acción política.

El conservadurismo imaginativo de Castoriadis se revela en su crítica al entronque materialista de la praxis marxista. Schmitt no comparte la ontología social de Marx; pero coincide con él en que la acción debe transformar la realidad empírica y no sólo las significaciones socialmente válidas. Schmitt está de acuerdo con Marx, en tanto, hay una realidad objetiva que, aparte de imponer mandatos de necesidad a los individuos y determinar el abanico de sus posibilidades reales, también es el lugar hacia el cual la acción propiamente política, que busca la transformación de lo dado, se objetiva y toma una dirección mediante hechos visibles y concretos, presentados a la vista pública y, por tanto, resueltos en el mundo compartido por todos.

En conclusión, Castoriadis puede ser visto como romántico político, en tanto defiende un accionismo radical del imaginario y pone en primer plano el lenguaje y el debate como el fundamento ontológico de la realidad social. Un tal cambio de las significaciones sociales es lo propio del conservadurismo romántico pues deja intacta la realidad empírica. Por eso, Schmitt sentencia al final de Romanticismo político que toda producción romántica en política, aunque sea creativa, se somete al poder de la realidad en la cual se encuentra y su superioridad sobre el presente en realidad es una actitud servil: "la verdad no se halla nunca en lo que el hombre individual concibe o quiere, porque todo es la función de una realidad que opera fuera de él” (Schmitt, 2005, p.143). El sujeto de Castoriadis aparentemente lo cambia todo, debido a su creatividad 
ilimitada; pero deja la realidad social más dura (la infraestructura de la sociedad capitalista) inalterada y se somete pasivamente a ella. Se trata de un "quietismo que puede ser caracterizado como pasividad legitimista, porque, si bien previamente ha vuelto inesencial lo dado en la realidad positiva, sin embargo, lo vuelve a reconocer como tal y no le permite ningún cambio" (Schmitt, 2005, p. 163).

Después de esta comparación entre Schmitt y Castoriadis en torno al rol de la imaginación productiva en la acción política, puede concluirse lo siguiente: el carácter políticamente conservador de la productividad estética está muy cerca de la pasividad práctica en política, conclusión aplicada por Schmitt, a los románticos alemanes; pero que vale para toda estetización de la política. En el Romanticismo, la capacidad creadora y transformadora de las redes simbólicas del lenguaje se equipará, de forma errónea, con los cambios en el mundo práctico.

La actividad política, entonces, deja de apuntar a la transformación de las circunstancias reales y materiales que afectan día tras día a los hombres, para interpretar de otro modo lo existente. En otras palabras, una acción política centrada en la imaginación resulta criticable pues desestima el tipo de compromiso absoluto con una causa y, a la par con esto, por sus presupuestos idealistas, no conduce a una transformación efectiva de la realidad. Entonces, en la medida en que Castoriadis centra su concepción de la acción política en la imaginación productiva también puede aplicársele la crítica de Schmitt al Romanticismo.

\section{Referencias bibliográficas}

Acosta, M. y Quintana L. (2010). De la estetización de la política a la comunidad desobrada. Revista de estudios sociales, 35, pp. $53-65$.

Aristóteles, (1995). Acerca del alma. Planeta - Agostini.

Benjamin, Walter, (2003). La obra de arte en la época de su reproductibilidad técnica. Editorial Ítaca.

Benjamin, Walter. (2000). El concepto de arte en el Romanticismo alemán. Ediciones Península.

Biemel, Walter. (1962). La ironía romántica y la filosofía del idealismo alemán. Convivium, $13-14$, pp. $27-48$.

Campe, R. (2016). Is "the political" a Romantic concept? En: J. Meierhenrich \& O. Simons. The Oxford Handbook of Carl Schmitt (pp.). Oxford University Press.

Castoriadis, Cornelius. (1989). La institución imaginaria de la sociedad 2. Tusquets editores. 
Castoriadis, Cornelius. (1991). Philosophy, Politics, Autonomy. Oxford University Press.

Castoriadis, Cornelius. (1993). Political and social writings: 1961 - 1979. University of Minnesota Press.

Castoriadis, Cornelius. (1994). Los dominios del hombre: las encrucijadas del laberinto. Editorial Gedisa.

Castoriadis, Cornelius. (1997). Ontología de la creación. Ensayo y Error.

Castoriadis, Cornelius. (1998). El ascenso de la insignificancia. Ediciones Cátedra.

Castoriadis, Cornelius. (2004). Sujeto y verdad en el mundo histórico-social. Fondo de Cultura Económica.

Castoriadis, Cornelius. (2005a). Figures of the thinkable. Disponible en internet: http:// www.notbored.org/FTPK.pdf.

Castoriadis, Cornelius. (2005b). The imaginary institution of society. Polity Press.

Castoriadis, Cornelius. (2005c). Escritos Políticos. Los libros de la catarata.

Castoriadis, Cornelius. (2010). A Society Adrift. Fordham university press.

Castoriadis, Cornelius. (2011). Historia y creación: textos filosóficos inéditos (1945 1967). Siglo Veintiuno Editores.

Curtis, David. (1997). The Castoriadis reader. Blackwell Publishers Ltda.

Diez, Luis Gonzalo. (2007). Anatomía del intelectual reaccionario: Joseph de Maistre, Vilfredo Pareto y Carl Schmitt: la metamorfosis fascista del conservadurismo. Biblioteca Nueva.

Dotti, Jorge y Pinto, Julio. (2002). Carl Schmitt: su época y su pensamiento. Eudeba.

Durst, David. (2004). Weimar modernism. Lexington Books.

El Ojeili, Chamsy. (2011). After Post-Socialism: Social Theory, Utopia, and the Work of Castoriadis in a Global Age. AntePodium, pp. 1 - 33. Disponible en internet: http:// www.victoria.ac.nz/atp/articles/pdf/ElOjeili-2011.pdf

Fichte, Johann. (2005). Introducciones a la doctrina de la ciencia. Editorial Tecnos.

Galfione, María Verónica. (2010). Estética y política: Consideraciones acerca de la crisis de la representación. Revista de Filosofía y Teoría Política, No 41, pp.67-98.

Gama, L. (2009). Arte y política como interpretación. Revista de estudios sociales, No. 34 , pp. $99-111$.

Habermas, Jürgen. (1993). El discurso filosófico de la modernidad. Taurus ediciones.

Hegel, G. W. F. (1989). Lecciones de estética. Ediciones 62 s.a.

Herrero, M. (2017). Teología Política y Representación en el pensamiento de Carl Schmitt. Revista de Filosofía Aurora, 29(47), pp. 377 - 403.

Joas, Hans. (1998). El pragmatismo y la teoría de la sociedad. Centro de investigaciones Sociológicas.

Kant, Inmanuel, (1981). Critica del Juicio. Espasa-Calpe.

Kant, Inmanuel, (1981). Critica de la razón pura. Editorial Losada.

Kierkegaard, S. (2000). Sobre el concepto de ironía. Editorial Trotta.

Klooger, Jeff (2009). Castoriadis: Psyche, Society, Autonomy. Brill.

Lilla, M. (2004). Pensadores temerarios. Random House.

Lowith, Karl. (2006). Heidegger, pensador en un tiempo ingente. Fondo de Cultura Económica.

Lypovestky, G. y Serroy, J. (2015). La estetización del mundo: vivir en la época del capitalismo artístico. Anagrama.

Malaver, José. (2005). La imaginación: fundamento de lo social-histórico y lo psíquico. (Tesis de maestría, Universidad del Valle, Cali, Colombia). 
Marder, M. (2010). Groundless Existence: The Political Ontology of Carl Schmitt. Continuum.

Mèlich, Joan-Carles, (1995). Las "esferas" de los valores. Ars Brevis, No. 1 pp. 145156.

Marx, C. y Engels, F. (1974). La ideología alemana. Ediciones Pueblos Unidos.

Paredes, Diego. (2009). De la estetización de la política a la política de la estética. Revista de Estudios Sociales, No. 34, pp. 91 - 98.

Ramírez, Carlos. (2009). "Todos son genios" La crítica a la estetización de la acción política en Carl Schmitt. Revista de estudios sociales, No. 34, pp. 59 - 91.

Rossi, Luis Alejandro. (2002). La lucha variaciones sobre un motivo. En J. Dotti, y J. Pinto. Carl Schmitt: su época y su pensamiento. Eudeba.

Scattola, M. (2008). Teología política: léxico de política. Nueva visión.

Schmitt, Carl. (1996). Roman Catholicism and Political Form. Connecticut: Greenwood Press.

Schmitt, Carl. (1998). El concepto de lo político. Alianza Editorial.

Schmitt, Carl. (2005). Romanticismo Político. Universidad de Quilmes.

Tormey, Simon y Townshend, Jules. (2006). Key thinkers from critical theory to postmarxism. Athenaeum Press.

Valdecantos, A. (2013) Juicio sin final. Acotaciones a las lecturas románticas de Carl Schmitt y Walter Benjamin. En A. Carrasco y A. Gomez. (2013) El fondo de la historia: Estudios sobre Idealismo alemán y Romanticismo. Dykinson.

Villacañas, José Luis, (2005). Poder y conflicto: Ensayos sobre Carl Schmitt. Editorial Biblioteca Nueva.

Weber, Max, (1978). Economy and society. University of California Press.

Weber, Max, (1997). Sociología de la religión. Editorial Istmo. 